\title{
The Diagnostic Accuracy of Mammography and Ultrasound in the Evaluation of Male Breast Disease: A New Algorithm
}

\author{
Zehra H. Adibelli ${ }^{\mathrm{a}}$ Ozgur Oztekin ${ }^{\mathrm{a}}$ Hakan Postaci $^{\mathrm{b}} \quad$ Adam Uslu $^{\mathrm{c}}$

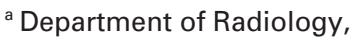 \\ ${ }^{\mathrm{b}}$ Department of Pathology, \\ ${ }^{\mathrm{c}}$ Department of General Surgery, Izmir Bozyaka Training and Research Hospital, Turkey
}

\section{Key Words}

Male breast cancer · Ultrasound - Mammography

\section{Summary}

Background: The purpose of this study was to define the diagnostic accuracy of mammography and ultrasound in the evaluation of male breast disease, and to suggest a diagnostic protocol for male breast disease. Material and Methods: We retrospectively reviewed clinical, radiographic, and pathologic records of 75 patients. Breast Imaging Reporting and Data System (BI-RADS) category 4-5 mammograms and ultrasonograms were suggested as suspicious for malignancy. Results: Of the 75 patients, $23(31 \%)$ were considered to have suspicious lesions by mammography and/or ultrasonography. 13 of the patients were shown to have breast cancer. The remaining $52(69 \%)$ were referred for biopsy by clinicians; all of the biopsy specimens were benign (gynecomastia). The accuracy data of mammography and ultrasonography are: sensitivity, 69 and 100\%; specificity, 87 and 97\%; positive predictive value, 53 and $87 \%$; negative predictive value, 93 and 100\%; and accuracy, 84 and 97\%, respectively. Conclusion: We suggest a new diagnostic algorithm for the evaluation of male breast disease in which ultrasonography may be used to evaluate palpable abnormalities as the first diagnostic tool of choice. To use and to trust imaging would decrease the number of falsepositive biopsies that would be generated by physical examination alone.

\author{
Schlüsselwörter \\ Brustkrebs des Mannes · Ultraschall - Mammographie
}

\section{Zusammenfassung}

Hintergrund: Ziel dieser Studie war es, die diagnostische Genauigkeit von Mammographie und Ultraschall bei der Beurteilung von Erkrankungen der männlichen Brust zu definieren sowie ein diagnostisches Protokoll für diese Erkrankungen vorzuschlagen. Material und Methoden: Die klinischen, radiologischen und pathologischen Unterlagen von 75 Patienten wurden retrospektiv begutachtet. Mammogaphien und Ultraschallaufnahmen der Breast Imaging Reporting and Data System (BI-RADS)Kategorien 4-5 wurden als verdächtig hinsichtlich einer bösartigen Erkrankung betrachtet. Ergebnisse: Mammographie und/oder Ultraschall zeigten verdächtige Veränderungen bei 23 (31\%) der 75 Patienten. Bei 13 dieser Patienten wurde Brustkrebs diagnostiziert. Die verbleibenden 52 (69\%) Patienten wurden von ihren behandelten Ärzten zur Biopsieentnahme überwiesen; alle dieser Biopsien waren gutartig (Gynäkomastie). Die Genauigkeitsdaten für Mammographie und Ultraschall sind wie folgt: Sensitivität 69 bzw. 100\%; Spezifität 87 bzw. 97\%; positiver Vorhersagewert 53 bzw. 87\%; negativer Vorhersagewert 93 bzw. 100\% sowie Genauigkeit 84 bzw. 97\%. Schlussfolgerung: Wir schlagen einen neuen diagnostischen Algorithmus für die Beurteilung von Erkrankungen der männlichen Brust vor, in welchem Ultraschall das erste diagnostische Mittel der Wahl zur Untersuchung palpabler Veränderungen ist. Die Nutzung von und das Vertrauen in die Bildgebung würde die Anzahl falschpositiver Biopsien verusacht durch alleinige ärztliche Untersuchung verringern.

\begin{tabular}{ll}
\hline KARGER & $\oplus$ 2009 S. Karger GmbH, Freiburg \\
Fax +49 761 4520714 & Accessible online at: \\
Information@Karger.de & www.karger.com/brc \\
www.karger.com &
\end{tabular}




\section{Introduction}

The incidence of breast cancer in men is much lower than in women, comprising about $1 \%$ of all breast cancers [1]. Between 1973 and 2000, the incidence of male breast cancer rose from 0.85 to 1.3 per 100,000 men; in the same time period, the incidence of female breast cancer increased from 98 to 135 per $100,000[2,3]$. Gynecomastia is much more common in men than breast cancer; in one series, $57 \%$ of the male population over 44 years of age had palpable breast tissue [3, 4]. Therefore, differentiation between benign and malignant masses is critical. Although mammography has been defined as the firstline diagnostic tool of choice in female patients, the utility of mammography in male patients with breast symptoms has not been established. Indeed, some clinicians ask 'When should men undergo mammography?' [5]. Some clinicians propose that mammography adds little diagnostic information to the clinical evaluation (the history and physical examination) [1]. This study was based on mammographic and ultrasonographic (US) findings of 75 histopathologically proven male patients. The purpose of this study was to define the diagnostic value of mammography and US in the evaluation of male breast disease, and to suggest a diagnostic protocol for male breast disease.

\section{Materials and Methods}

Between January 1999 and December 2008, mammography and US were performed in our Mammography Unit on 164 male patients, 75 of whom underwent biopsy. In this study, 75 histopathologically proven male patients were retrospectively evaluated. Institutional Review Board approval was obtained prior to commencement of the study. Individual patient informed consent for this retrospective study was not required. The clinical and pathologic records of these patients were reviewed from the archive system of our hospital. The data, including questionnaires, mammograms, US prints, and reports, were recorded and archived in the Mammography Unit. All of the patients were first seen by clinicians and then referred for mammography. Mammography was performed using a Senographe $700 \mathrm{~T}$ (General Electric Medical Systems, Milwaukee, USA). The standard mammographic views (craniocaudal and mediolateral oblique) of each breast were routinely obtained. Magnification and spot compression views were also used as deemed necessary.

Mammograms were read in a blinded fashion by 2 radiologists with experience in breast imaging of 2 and 10 years. The radiologists examined each mammogram independently and made a diagnosis based on the American College of Radiology BI-RADS (Breast Imaging Reporting and Data System) lexicon [6]. Mammograms were reviewed for the presence of gynecomastia and masses (shape, margin, density, size, and location), morphologic characteristics, distribution of calcifications, and associated findings such as skin, nipple, or pectoralis muscle involvement. Discordant mammographic interpretations were subsequently resolved by consensus of the 2 radiologists. BI-RADS 1, 2, and 3 were negative, benign, and probably benign, respectively. Gynecomastia was suggested as BI-RADS category 2; BI-RADS 4 and 5 were suspicious and highly suggestive of malignancy, respectively.

US was performed using high-resolution ultrasound equipment (GE Logiq S6, General Electric Medical Systems; Sonoscape SSI-2000 BW, Shenzhen, China; Mindray DP-9900, Shenzhen; or Toshiba Sonolayer
SSA-270A, Tokyo, Japan) with 8-12 MHz, 5-13 MHz, 6-8.5 MHz, and 7.5 $\mathrm{MHz}$ transducers, respectively by 1 of 10 attending radiologists in breast sonography. In the case of a mass, the type of lesion (solid, complex, cystic, or pure cystic), the location, size, echogenicity, contour, and acoustic features were evaluated, and the presence of axillary lymph nodes was noted. The sonographic findings were categorized into 4 groups: (A) gynecomastia; (B) negative, if no discrete abnormality was found; (C) a cystic mass; and (D) a solid mass. Groups A, B, and C corresponded to the current American College of Radiology Ultrasound BI-RADS [7] categories $1-3$, and group D to BI-RADS 4 and 5. The BI-RADS 4 and 5 mammographic and US assessments were considered suspicious for malignancy and recommended for biopsy. Mammography of BI-RADS categories 1-3 were considered negative if no solid mass was found on US. Negative sonograms and simple cysts were considered negative sonographic findings.

Confirmed tissue diagnoses were obtained with 71 surgical specimens (18 mastectomies and 53 excisional biopsies) and 4 fine needle aspirations (FNA). All of the cases in which FNA was performed were diagnostic. Tissue diagnoses were confirmed by 1 pathologist with 20 years of experience. Sensitivities, specificities, and positive and negative predictive values were calculated using the following formulas [8]: sensitivity $(\mathrm{Sn})=$ $\mathrm{TP} / \mathrm{TP}+\mathrm{FN}$; specificity $(\mathrm{Sp})=\mathrm{TN} / \mathrm{TN}+\mathrm{FP}$; positive predictive value $(\mathrm{PPV})$ $=\mathrm{TP} / \mathrm{TP}+\mathrm{FP}$; negative predictive value $(\mathrm{NPV})=\mathrm{TN} / \mathrm{TN}+\mathrm{FN}$; and accuracy $(\mathrm{Ac})=\mathrm{TP}+\mathrm{TN} / \mathrm{TP}+\mathrm{TN}+\mathrm{FP}+\mathrm{FN}$. TP is the number of true positives, $\mathrm{TN}$ is the number of true negatives, FP is the number of false positives, and $\mathrm{FN}$ is the number of false negatives.

\section{Results}

The age range of the patients in the study was 13-81 years, with a mean of 45.2 years. The presenting symptoms were diffuse bilateral or unilateral breast enlargement without a palpable mass in 21 patients $(28 \%)$, a mass or thickening in 59 patients $(79 \%)$, and pain in $19(25 \%)$ of the patients. Some of the patients had more than 1 symptom.

In our series, there were 13 cases of male breast cancer. Their ages ranged between 38 and 81 years (mean, 59.7 years). Histopathologically, the size of the masses ranged between 0.5 and $5 \mathrm{~cm}$ (mean, $2.4 \mathrm{~cm}$ ), and metastases to axillary lymph nodes existed in 5 patients. A previous contralateral breast carcinoma was present in 1 case, and prior irradiation of the chest was present in another case due to lung cancer. In 1 case, 8 years after surgery, an ipsilateral breast cancer had relapsed.

On mammography, 54 patients $(72 \%)$ were categorized as BI-RADS 1 and 2. Histopathologically, in this group, breast carcinoma was found in 2 patients (fig. 1) and gynecomastia in 52 patients. Four patients (4\%) were considered to have BI-RADS 3, and pathologically 2 breast carcinomas, 1 fibroadenoma, and 1 epidermal inclusion cyst were demonstrated. The pathologic results for the 17 men categorized as mammography BI-RADS 4-5, were breast carcinomas in 9 patients, fibrocystic disease of the breast in 2 patients, and gynecomastia in 6 patients (table 1). A mass with microcalcifications was seen on mammography in 1 case $(9 \%)$. The location of the masses was retroareolar in 7 patients $(64 \%)$ and eccentric to the nipple in 4 patients $(36 \%)$. The contours of the masses 

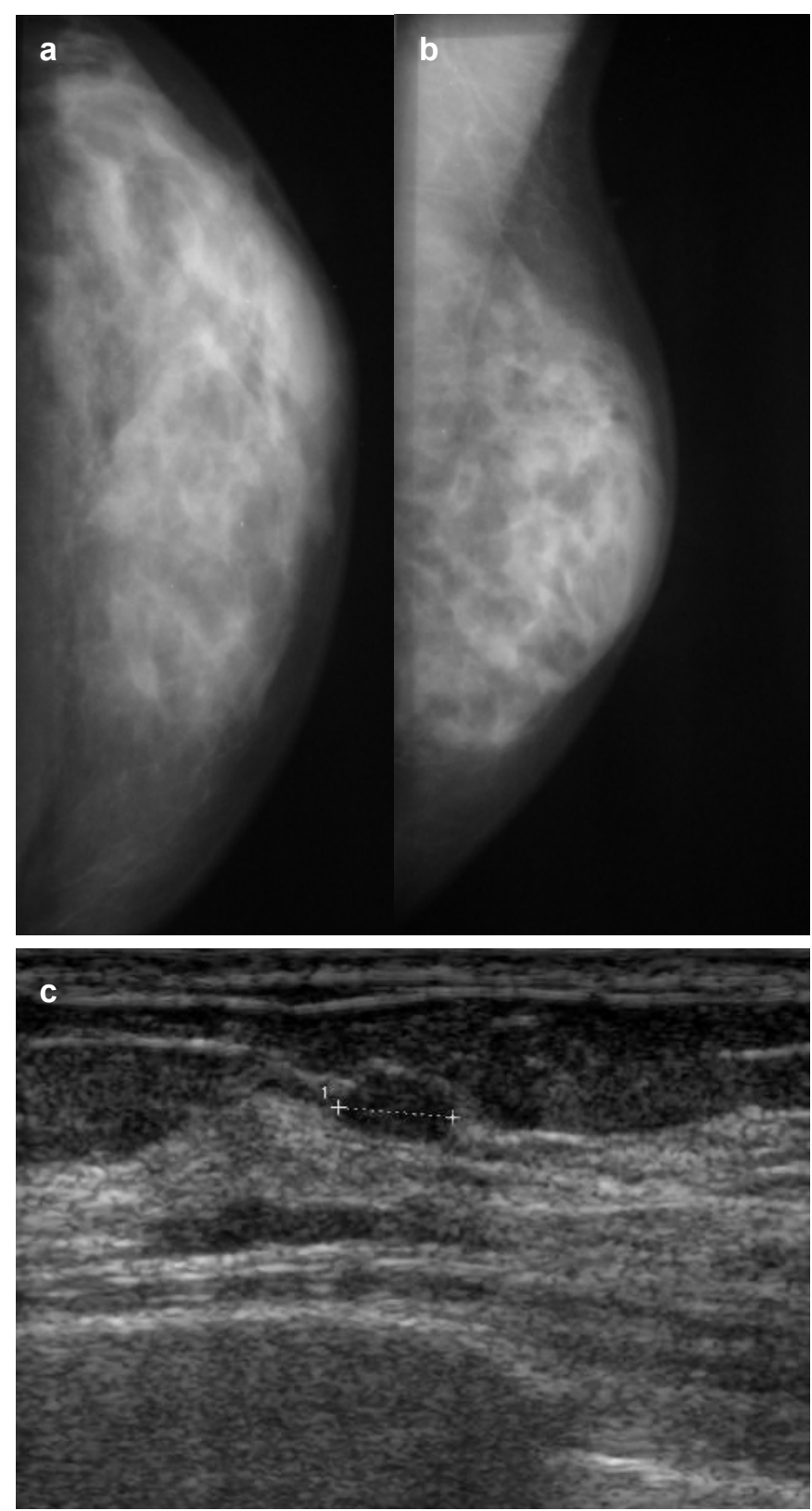

Fig. 1. Invasive ductal carcinoma in a 39-year-old man. a Craniocaudal and $\mathbf{b}$ mediolateral oblique mammograms show heterogeneously dense breast similar to a female breast. It is impossible to demonstrate any mass. c Ultrasound demonstrates a solid, hypoechoic mass of $0.8 \mathrm{~cm}$.

were irregular in 9 patients (82\%; fig. 2), and well-circumscribed in 2 patients $(18 \%)$.

On US, 55 patients (73\%) had BI-RADS 1 and 2 and the pathologic diagnosis was gynecomastia in all patients. Five patients who were classified as BI-RADS 3 were histologically proven to have gynecomastia (3 patients) and fibrocystic disease of the breast ( 2 patients). Among the 15 patients with suspicious ultrasound features, histological assessment demonstrated 13 breast carcinomas, 1 fibroadenoma and 1 epidermal inclusion cyst (table 2). The mammographic and US BI-RADS categories are demonstrated in table 3.

Table 1. Mammographic and pathologic correlations of the patients

\begin{tabular}{llcl}
\hline $\begin{array}{l}\text { BI-RADS } \\
\text { mammography }\end{array}$ & \multicolumn{2}{l}{ Histology, $\mathrm{n}(\%)$} & Total, $\mathrm{n}(\%)$ \\
\cline { 2 - 3 } & Cancer & Benign biopsy & \\
\hline 1,2 & 2 & 52 & $54(72)$ \\
3 & 2 & 2 & $4(5)$ \\
4,5 & 9 & 8 & $17(23)$ \\
Total & $13(17)$ & $62(83)$ & $75(100)$ \\
\hline
\end{tabular}

Table 2. Ultrasonographic and pathologic correlations of the patients

\begin{tabular}{llcc}
\hline $\begin{array}{l}\text { BI-RADS } \\
\text { ultrasound }\end{array}$ & \multicolumn{2}{l}{ Histology, $\mathrm{n}(\%)$} & Total, $\mathrm{n}(\%)$ \\
\cline { 2 - 3 } & Cancer & Benign biopsy & \\
\hline 1,2 & 0 & 55 & $55(73)$ \\
3 & 0 & 5 & $5(7)$ \\
4,5 & 13 & 2 & $15(20)$ \\
Total & $13(17)$ & $62(83)$ & $75(100)$ \\
\hline
\end{tabular}

Table 3. Mammography versus ultrasound in 75 patients

\begin{tabular}{llrr}
\hline Mammography & \multicolumn{2}{l}{$\begin{array}{l}\text { Ultrasonographic } \\
\text { BI-RADS }\end{array}$} & \multicolumn{2}{c}{ Total, $\mathrm{n}$} \\
\cline { 2 - 3 } & $1,2,3$ & \\
\cline { 2 - 3 } & 52 & 2 & 54 \\
1,2 & 0 & 4 & 4 \\
3 & 8 & 9 & 17 \\
4,5 & 60 & 15 & 75 \\
\hline
\end{tabular}

Twenty-three $(31 \%)$ of the 75 patients were considered suspicious by mammography and/or US; all of the patients underwent biopsy (13 mastectomies, 8 excisional biopsies, and 2 FNA). Thirteen patients were found to have breast cancer (invasive ductal carcinoma) pathologically. The remaining 10 biopsy results were benign, including diagnoses of gynecomastia (6), fibroadenoma (1), epidermoid inclusion cyst (1), and fibrocystic disease of breast (2). Fifty-two (69\%) of the 75 men were referred for biopsy (5 mastectomies, 45 excisional biopsies, and 2 FNA) by clinicians because of esthetic reasons (5 patients), abnormal palpation (44 patients), or suspected invasion by known primary malignancies ( 3 patients). All of them were benign, and the diagnosis of 52 patients was gynecomastia. On mammography, all of them were reported as gynecomastia; 24 patients had the nodular type, 15 patients had the dendritic type, and 13 patients had diffuse-type gynecomastia and no suspicious lesions were demonstrated.

The accuracy data for mammographic BI-RADS 4 and 5, BI-RADS 3, 4, and 5 (when mammographic BI-RADS 3 findings, such as well-circumscribed lesions, are considered as suspicious), and sonographic BI-RADS 4 and 5 are summarized in table 4 . 
Fig. 2. Invasive ductal carcinoma in a 74-yearold man. a Mediolateral oblique mammogram shows large, retroareolar, lobulated, high-density mass with an axillary lymph node. Ipsilateral axillary lymph node metastasis was found pathologically. b Ultrasound of the mass shows solid, lobulated and heterogeneous mass.

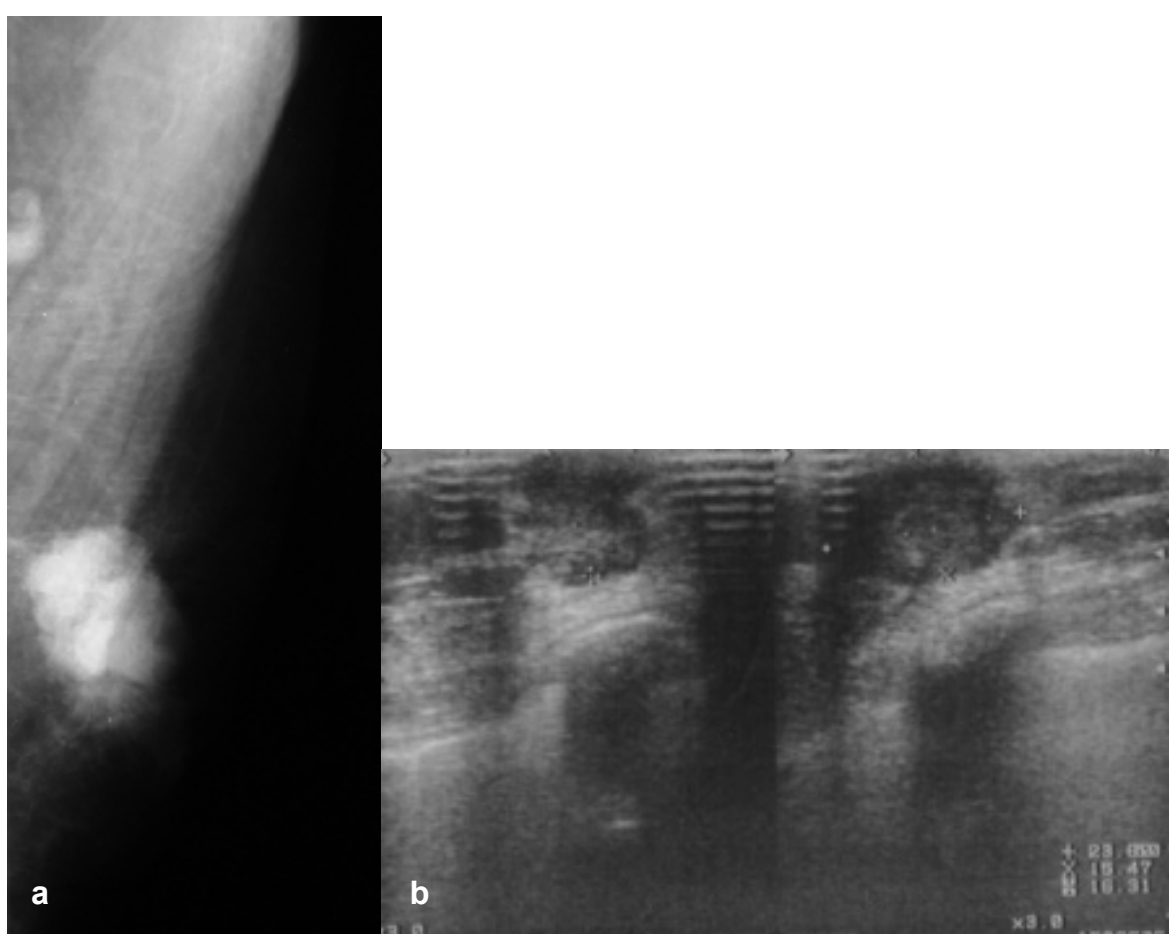

Table 4. Summary of accuracy data for mammographic BI-RADS 4, 5; BI-RADS 3, 4, 5; and sonographic BI-RADS 4, 5

\begin{tabular}{lcllll}
\hline & $\mathrm{Sn}, \%$ & $\mathrm{Sp}, \%$ & $\mathrm{PPV}, \%$ & $\mathrm{NPV}, \%$ & $\mathrm{Ac}, \%$ \\
\hline $\begin{array}{c}\text { BI-RADS 4 and 5 } \\
\text { (mammographic) }\end{array}$ & 69 & 87 & 53 & 93 & 84 \\
$\begin{array}{c}\text { BI-RADS 3, 4 and 5 } \\
\text { (mammographic) }\end{array}$ & 85 & 84 & 52 & 96 & 84 \\
$\begin{array}{c}\text { BI-RADS 4 and 5 } \\
\text { (ultrasound) }\end{array}$ & 100 & 97 & 87 & 100 & 97 \\
\hline
\end{tabular}

$\mathrm{Sn}=$ Sensitivity; $\mathrm{Sp}=$ specificity $\mathrm{PPV}=$ positive predictive value; $\mathrm{NPV}=$ negative predictive value; $\mathrm{Ac}=$ accuracy.

\section{Discussion}

In the middle-aged adult male population, breast tissue is palpable in $30 \%$ or more, and with advancing age, the presence of palpable breast tissue increases to $60 \%$ or more by the 7th decade [9]. Gynecomastia is one of the most common male breast complaints $[1-4,9,10]$. Although rare and accounting for less than $1 \%$ of all breast cancers, the incidence of breast carcinoma in men has increased, as in women $[1,2]$. Breast cancer in men must be differentiated from benign breast diseases. A proven appropriate algorithm for the evaluation of male breast disease has not been defined.

In our series, the most common mammographic finding was gynecomastia, as in other reports [10-12]. Gynecomastia has been described to be co-existent with breast cancer and obscure it $[12,13]$. In our study, on mammography, 11 of 13 masses (85\%) were demonstrated ( 9 as BI-RADS 4 and 5, and 2 as BI-RADS 3). Gynecomastia existed in 3 breast cancers $(23 \%)$. One of our cases of cancer was masked by gynecomastia, even in retrospect (fig. 1). The other missed mass belonged to the patient who had ipsilateral breast cancer, and it was demonstrated only on US. The size of that mass was $0.5 \mathrm{~cm}$ and because of the prior operation, mammography could not be performed on that patient successfully.

In our series, the findings about the location and the contour of the masses and the nipple changes are concordant with previous reports by Gunhan-Bilgen et al. [10] and Mathew et al. [14]. As described in the literature, it is very important that well-circumscribed masses should be considered with suspicion in men because they can be cancer [10,11, 14, 15].

All tumors were ductal in origin, as in the literature. In our series, there was a case who had ductal carcinoma in situ (DCIS) of the papillary subtype associated with invasive carcinoma and he had lobulated masses on mammography and US. There were no cases of pure DCIS. The reason why we had no cases of pure DCIS might be the late evaluation for breast masses. Pure DCIS in men without an associated infiltrating carcinoma is less common in the literature $(2.3-17 \%)$ [10, 16, 17]. Compared with DCIS in the female breast, distinct clinical and morphologic differences have been suggested. The two most characteristic symptoms described for DCIS in men are a slowly-growing subareolar mass and serosanguineous nipple discharge, whereas the typical feature of DCIS in women involves microcalcifications [16]. However, in cases where the only feature of DCIS in men is microcalcifications, although it 
is extremely rare, making a diagnosis with US alone results in some misdiagnoses.

In our study, 1 patient had a fibroadenoma and corresponded to BI-RADS 3 on mammography. Because of the solid character on US, it was considered suspicious for malignancy. Two of our patients had fibrocystic diseases of the breast pathologically. On mammograms, both of them had diffuse gynecomastia and local architectural distortion, which corresponded to BI-RADS 4. On US, local ductal dilatations were demonstrated. Fibroepithelial lesions are uncommon in the male breast. Fibroadenomas are very common in female breasts, but are exceedingly rare in the male breast [18].

In our series, masses were visible in $100 \%$ of patients with cancer by US. In cases with negative US, no cancer was found; however, 2 carcinomas were found in the patients with mammography BI-RADS category 3 , and 2 cancers were found in categories 1 or 2 pathologically. Cases of carcinoma found by US that were obscured on mammography by gynecomastia have been described previously $[10,11]$. In the literature, reports of US evaluation of male breast disease are limited and mostly descriptive $[10,11,17]$. US was the most sensitive indicator for breast carcinoma in our series, with better sensitivity and specificity than mammography, even if we evaluated BI-RADS 3 category as suspicious. The NPV of $100 \%$ for US suggests that sonograms read as normal or negative need no further examination if the clinical findings are not suspicious. There were several limitations to our study. It was a single institution data set, and the patients were retrospectively reviewed. US was performed after mammography. Also, the number of patients was small.

In conclusion, US is a low-cost, accurate, diagnostic modality, and can be used to differentiate benign and malignant processes of male breast disease. The sensitivity, specificity, and accuracy of US were satisfactory and superior to mammography. US can reliably identify male breast malignancy. However, the number of patients in our study was not sufficient to make a definitive recommendation to exclude mammography in the diagnosis of male breast disease. US may be used to evaluate palpable abnormalities of the male breast as the first-line diagnostic tool of choice. When US findings are suspicious, tissue diagnosis is performed. Mammography is used when US findings are indeterminate. If mammography findings are suspicious or indeterminate for malignancy, tissue diagnosis is recommended. We suggest a new preliminary diagnostic algorithm; however, a new protocol should be evaluated by further studies. A reliable and proven diagnostic approach will decrease the number of false-positive biopsies that would be generated by physical examination alone.

\section{Conflict of Interest}

The authors indicate that they have no interest which may be perceived as posing a conflict or bias.

\section{References}

$\checkmark 1$ Hines SL, Tan WW, Yasrebi M, DePeri ER, Perez EA: The role of mammography in male patients with breast symptoms. Maya Clin Proc 2007;82:297300 .

2 Chantra P, So G, Wollman J, Basset L: Mammography of the male breast. AJR 1995;164:853-858.

3 Kopans D: Breast Imaging, 3rd ed. Philadelphia, PA, Lippincott Williams and Wilkins, 2007, pp. 671-672.

4 Nutall FQ: Gynecomastia as a physical finding in normal man. J Clin Endocrinol Metab 1979;48:338340 .

5 Munn S: When should men undergo mammography? AJR 2002;178:1419-1420.

6 American College of Radiology (ACR): ACR BIRADS, mammography; in ACR Breast Imaging Reporting and Data System: Breast Imaging Atlas, 4th ed. Reston, VA, American College of Radiology, 2003.

7 American College of Radiology (ACR): Breast Imaging Reporting and Data System: Ultrasound. Reston, VA, American College of Radiology, 2003.
8 GoldmanL: Quantitative aspects of clinical reasoning; in Isselbacher KJ, Braunwald E, Wilson JD, et al. (eds): Harrison's Principles of Internal Medicine, 13th ed. New York, NY, McGraw-Hill, pp. 9-14.

-9 Daniels IR, Layer GT: How should gynaecomastia be managed? ANZ J Surg 2003;73:213-216.

10 Gunhan-Bilgen I, Bozyaka H, Ustun EE, Memis A: Male breast disease: clinical, mammographic, and ultrasonographic features. Eur J Radiol 2002;43: 246-255.

11 Patterson S, Helvie M, Aziz K, Nees AV: Outcome of men with clinical breast problems: the role of mammography and ultrasound. Breast J 2006;12: 418-423.

12 Evans GFF, Anthony T, Appelbaum AH, Schumpert TD, Levy KR, Amirkhan RH, Cambell TJ, Lopez J, Turnage RH: The diagnostic accuracy of mammography in the evaluation of male breast disease. Am J Surg 2001;181:96-100.

13 Appelbaum AH, Evans GF, Levy KR, Amirkhan RH, Schumpert TD: Mammographic appearances of male breast disease. Radiographics 1999;19:559568 . 